\title{
Thoracic surgery in Palestine
}

\author{
Mayar Ishaq Idkedek ${ }^{1}$, Bayan Fathi Al-Qtishat ${ }^{1}$, Bisanne Hamdi Shaqqura ${ }^{2}$, Firas Emad Abu Akar ${ }^{2}$
}

${ }^{1}$ Medical Research Club, Faculty of Medicine, Al-Quds University, Jerusalem, Palestine; ${ }^{2}$ Department of Cardiothoracic Surgery, Makassed Charitable Society Hospital, East Jerusalem, Palestinian Territories

Contributions: (I) Conception and design: MI Idkedek, BF Al-Qtishat; (II) Administrative support: All authors; (III) Provision of study materials or patients: MI Idkedek, BF Al-Qtishat; (IV) Collection and assembly of data: MI Idkedek, BF Al-Qtishat; (V) Data analysis and interpretation: MI Idkedek, BF Al-Qtishat; (VI) Manuscript writing: All authors; (VII) Final approval of manuscript: All authors.

Correspondence to: Firas Emad Abu Akar. Department of Cardiothoracic Surgery, Makassed Charitable Society Hospital, 28 Raba'a Adaweieh street, Mount of olives, East Jerusalem 90917, Palestinian Territories. Email: firasabuakar@gmail.com.

\begin{abstract}
Thoracic surgery in Palestine ran across a significant shift in the past couple of years, moving from performing all surgeries by open thoracotomy incision to the current rate of more than two-thirds of surgeries being conducted using Uniportal video-assisted thoracic surgery (VATS). Thoracic surgeons most commonly deal with lung cancer, followed by chest trauma, inflammatory or infectious diseases, and congenital malformations of the chest. One of the most prominent strengths that Palestinian thoracic surgeons have is their extensive experience in managing trauma and hydatid cyst patients. While the limited number of thoracic surgeons, the complex referral process between governmental and private hospitals, and the late presentation of lung cancer patients are considered the specialty's weaknesses. Despite the challenges that thoracic surgeons face, they aim to overcome them by establishing lung cancer screening programs and enhancing the role of the primary healthcare system in order to achieve better outcomes in early diagnosed patients. Moreover, thoracic surgeons are relentlessly determined to take part in global research and publish their most notable contributions to share their experiences and prove that they can make a real change. Finally, the authors emphasize establishing a well-constructed thoracic surgery unit, which also includes a residency training program to ensure self-sufficiency in the future by having national graduates who will be the leading providers and researchers.
\end{abstract}

Keywords: Uniportal video-assisted thoracic surgery (uniportal VATS); lung cancer; thoracic trauma; surgery in Palestine

Submitted Jul 10, 2021. Accepted for publication Oct 19, 2021.

doi: $10.21037 /$ jtd-21-1139

View this article at: https://dx.doi.org/10.21037/jtd-21-1139

\section{Introduction}

Thoracic surgery is considered one of the continuously evolving specialties, with ongoing development and improvements of its surgical techniques, ranging from performing open thoracotomies and multiportal video-assisted thoracic surgery (VATS) for lung resections to the minimally invasive Uniportal VATS that is implemented nowadays (1).

However, thoracic surgery in Palestine-as a developing country - was somehow an undeveloped specialty, in which lung pathologies were treated using the traditional open thoracotomy incision. Fortunately, since 2017, simple and complicated cases of Uniportal VATSs have been applied by four experienced thoracic surgeons.

In this article, the authors give an overview of the thoracic surgery situation in Palestine, the most commonly treated diseases by surgeons in the field, the specialty's strengths and weaknesses, in addition to the thoracic surgeons' research experience, and future vision.

\section{Overview of the Palestinian healthcare system}

Palestine is a developing country in the Middle East with an extremely complicated political situation for decades. 
Geographically, Palestine is divided into three parts: East Jerusalem, West Bank, and Gaza strip. The Palestinian population is considered an expansive population with 5.1 million inhabitants as of 2020 .

Healthcare in Palestine is delivered to the population by two sectors: a governmental and a private sector.

In the governmental sector, health care is provided with minimal or no cost by governmental insurance, which is offered to people at a very affordable cost paid yearly, or it may be provided for free for certain social groups such as the unemployed.

Each province has a governmental hospital with an emergency department and at least two floors for internal medicine and general surgery. Government hospitals can be small and only include the mentioned above departments or include a wide variety of specialties, such as ophthalmology and thoracic surgery.

The private sector encompasses more specialized tertiary hospitals with more comprehensive specialty options; thus, it is costly and not directly covered by governmental insurance. Such hospitals require private insurance and special referral from the government hospitals to ensure coverage from governmental insurance; otherwise, patients will have to pay out of their pocket.

Unfortunately, both sectors lack primary health care infrastructure, which constitutes a real challenge on early diagnosis and treatment of many diseases, as we will discuss later.

The Palestinian older generation's health is generally burdened with cardiovascular, cerebrovascular diseases and malignancies, while the youthful generations are burdened with trauma and gunshots.

As for the causes of mortality, cardiovascular diseases are the most common cause of death, followed by diabetes mellitus complications, while cancer deaths come in third place. In 2020, Lung Cancer was the most common cause of mortality among cancers in Palestine, followed by colon and breast cancers, respectively (2).

\section{Common diseases encountered by thoracic surgeons in Palestine}

Thoracic surgery represents a highly specialized field that aims to provide operative and perioperative care for patients having congenital, acquired or traumatic diseases in their chest (3).

Thoracic surgeons -in governmental and private sectorsusually treat the following four broad spectra of diseases:
* Oncological diseases of lungs, pleura, chest wall, esophagus, and thymus-diagnostic and therapeutic procedures;

* Inflammatory and infectious diseases include bullous emphysema, bronchiectasis, empyema, hydatid cysts, and lung abscesses;

* Chest wall trauma, road traffic accidents, gunshots, and associated complications such as organ injuries, traumatic pneumothorax, and hemothorax;

* Congenital malformations of lungs, chest wall, esophagus, and diaphragm.

Oncological diseases are considered the first most commonly treated in thoracic surgery in Palestine. While chest wall trauma is considered to be the second most common condition.

Among oncological diseases, lung cancer is the most treated malignancy. It has an incidence rate of 9.3/100,000 population, representing the third most common cancer in Palestine (4).

According to thoracic surgeons in Palestine, almost 60 $90 \%$ of lung cancer patients presented to thoracic surgeons are considered operable cases, with an average of 200-300 patients receiving surgeries for lung cancer. The number of operable patients refers to those who are fit to undergo surgery and have not been referred to the oncology, pulmonology, or palliative care clinics.

\section{The delivery of thoracic surgery services: from surgeons to patients}

Thoracic surgery services in Palestine are delivered in a coordinated fashion between the two splits of the healthcare system. However, it is important to look over each sector separately regarding hospitals, surgeons' number, and specialty, their preferred approach, and the number of operations per year.

Three governmental hospitals provide thoracic surgery services; one is located in the West Bank and is served by one vascular and thoracic surgeon. The other two hospitals are located on Gaza strip and are served by a specialized thoracic surgeon. Therefore, there are three surgeons in the governmental hospitals, each providing 200-250 surgeries per year.

As for the private sector, there is one hospital in the West Bank and two in East Jerusalem; three specialized thoracic surgeons serve these (Figure 1). The private sector provides a more advanced approach in thoracic surgery, such as the use of uniportal VATS even in the pediatric population (5-7). 


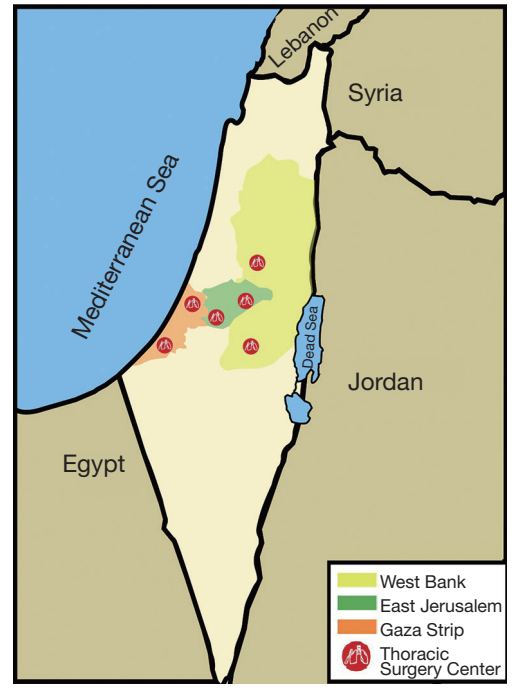

Figure 1 A map showing the distribution of hospitals that have departments or units specialized in thoracic surgery in Palestine.

According to thoracic surgeons and the statistics of their departments, each surgeon in the private sector performs approximately 100-150 surgeries per year, compared to 300 surgeries/year in the corresponding author working center (Al-Makassed Hospital), which is recognized as the leading hospital in minimally invasive thoracic surgery in our area.

Uniportal VATS approach was first introduced to the Palestinian health system by Dr. Firas Abu Akar after his return from clinical fellowship in minimally invasive thoracic surgery at Shanghai pulmonary hospital. A team consisting of an anesthesiologist and two nurses were sent to the hospital in Shanghai for 2 weeks in order to be trained on how to perform the new technology. Then, Al-Makassed Hospital started to purchase the required equipment gradually and Dr. Abu Akar began to perform the minimally invasive technique on simple and complicated cases (8).

Moreover, the uniportal VATS technique was promoted by Dr. Abu Akar through organizing conferences, workshops and experimental wet labs for the Palestinian and Israeli thoracic surgeons (Figure 2) and visiting Gaza Strip continuously every 2-3 months to perform operations and to teach his colleagues there (Figure 3).

And of course, this scenario will be repeated for other thoracic surgeons as they obtain their training outside of Palestine and return to share either knowledge and skills with their affiliates.

To summarize, thoracic surgery services are provided in six centers able to perform 1,000 thoracic surgery per year, with uniportal VATS being the most prevalent surgical approach used with a prevalence rate of $70-80 \%$, and followed by posterolateral thoracotomies.

As for the patients, the interplay between the governmental and private sectors in thoracic surgery and the lack of a primary health care system makes the journey to get the needed thoracic surgery services somehow long.

The process usually starts with an internist, surgeon, or a general physician, depending on the patients' chief complaint and his/her provider of preference, who usually refers the patient to a governmental surgery clinic for further evaluation. Suppose the patient requires thoracic surgery services; two options are available: referral to the private sector or primary governmental hospitals that provide some but not all thoracic surgery services.

After the long and hefty process of referrals between hospitals, the average operation time of a uniportal VATS is $2-3$ hours and maybe less than 1 hour in a simple lobectomy, while the uniportal VATS has surgical mortality of less than $1 \%$ and a length of stay 2-3 days, as compared to 4-6 days in open thoracotomies.

\section{Clinical practice: highlights and challenges}

After the lengthy discussion of the thoracic surgery services delivery, surgical approach, and the surgeon-patient interplay, the authors focus on the highlights and challenges of clinical practice in Palestine that can be dissected as the specialty's strengths and weaknesses.

As for the specialty's strengths, they can be concluded in the following: conducting simple and complicated uniportal VATS, performing minimally invasive chest wall reconstruction and deformities repair, multidisciplinary team working on complicated cases in the thorax, in addition to the availability of high job opportunities in the field due to the limited number of specialists.

Moreover, one of the most prominent strengths of thoracic surgery in Palestine is experienced surgeons in trauma patients and hydatid cyst management.

A study conducted at Al-Makassed Charitable Hospital (9) concluded that managing pulmonary hydatid cysts with Uniportal VATS resulted in less surgical trauma, air leak, post-operative drain, and post-operative pain consistent with the published literature (10). The clinical significance of this study further confirms that Palestinian thoracic surgeons' experience in this disease is high, specifically when it comes to using Uniportal VATS as the treatment instead of open thoracotomy, with emphasis on hydatid cyst being more 


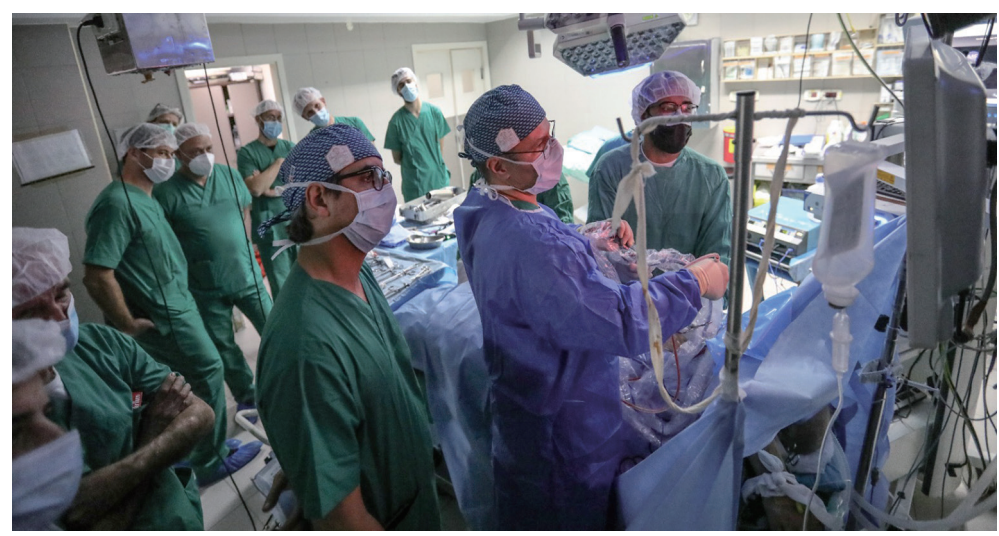

Figure 2 A masterclass in uniportal VATS technique held at Al-Makassed Hospital 2020. VATS, video-assisted thoracic surgery.

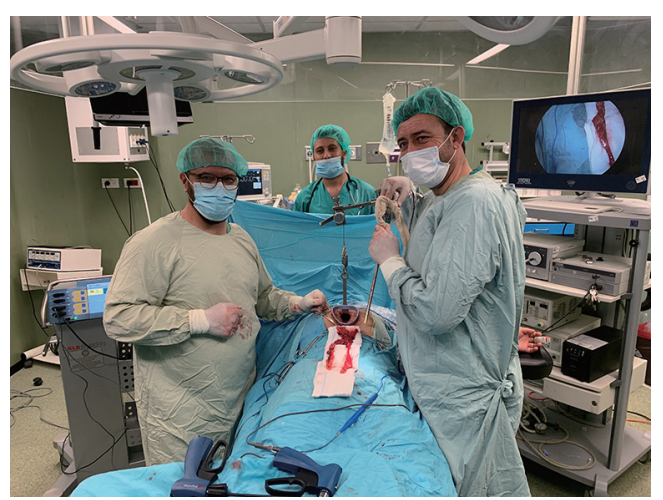

Figure 3 Training surgeons in the Gaza Strip on the uniportal VATS technique. VATS, video-assisted thoracic surgery.

common in Palestine compared to the Western world.

On the other hand, late presentation of patients with malignancies, complex referrals between governmental and private hospitals, a limited number of thoracic surgeons, and high cost of operations in patients with no insurance are considered the weaknesses of thoracic surgery in Palestine.

The main challenges hindering the achievement of optimal thoracic surgery services are mainly the authors' weaknesses, which should be faced to ensure the appropriate management of patients.

Another critical challenge is: the absence of a residency program in thoracic surgery in Palestinian hospitals, with the general surgery residents, only spend approximately 1-2 months in the thoracic surgery department.

Furthermore, the political situation in Palestine represents a unique challenge. It requires a special mention, as the movement restrictions imposed on the Palestinian population restrain their rights to receive the best care option. Moreover, the long waiting time to obtain permits to enter specific regions of the country delays cancer treatment, leading to previously discussed percentages of inoperable patients (11).

\section{Research experience and vision}

The progress of research in the thoracic surgery field is highly associated with the development of clinical practice, with both parts complementing each other. As clinical practice has been evolving in Palestine, research conducted by surgeons, residents, and students has also been growing in parallel with improving practice.

Thoracic surgeons and their teams tend to publish their most notable contributions, even with the somewhat limited research in Palestine. The most common focus is on publishing complicated cases of uniportal VATS, reporting uniportal VATS lobectomy in pediatrics (12), in addition to publishing original articles and other case reports (7).

The authors highly believe that a prosperous future will depend on contributions in the research field and clinical practice and require overcoming the challenges mentioned above, which may conceal the thoracic surgeons' honorable efforts if not faced and solved effectively.

Thus, the authors endeavor to start applying the recommended screening program for lung cancer and strengthen the construction of the primary health care system to move one step closer to solving the issue of late diagnosis.

Additionally, significant efforts are made in order to prepare for establishing a thoracic surgery unit with more beds, ICU units in addition to establishing a residency program, which will ensure better care provided to patients, 
more opportunities for young physicians in Palestine, and of course giving the lead to the new generation of surgeons who can learn and practice the new VATS techniques quickly and perfectly.

\section{Conclusions}

Thoracic surgery practice in Palestine is a reflection of the healthcare system in the country. It is directly affected by the factors that affect the healthcare system, whether the positive influences or the points that require further work and improvement.

As the authors have alluded to, this specific specialty has been advancing as clinical and research practice over the past few years; evidenced by the increasing number of publications regarding the procedures delivered accustomed to the Palestinian population.

With all the advancements made, thoracic surgeons still deal with many existing challenges, working on complicated cases with minimal resources in a developing country, improving the quality of care, and ensuring the best outcome for patients.

When faced by perseverance and highly ambitious doctors, these challenges will lead to the progress thoracic surgery is witnessing in Palestine, as this field of thoracic surgery is going on an upward trajectory.

\section{Acknowledgments}

We want to thank the providers of thoracic surgery in Palestine for kindly sharing their experiences with us.

Funding: None.

\section{Footnote}

Provenance and Peer Review: This article was commissioned by the Guest Editor (Alan D. L. Sihoe) for the series "Thoracic Surgery Worldwide" published in Fournal of Thoracic Disease. The article has undergone external peer review.

Peer Review File: Available at https://jtd.amegroups.com/ article/view/10.21037/jtd-21-1139/prf

Conflicts of Interest: All authors have completed the ICMJE uniform disclosure form (available at https://jtd.amegroups. com/article/view/10.21037/jtd-21-1139/coif). The series "Thoracic Surgery Worldwide" was commissioned by the editorial office without any funding or sponsorship. The authors have no other conflicts of interest to declare.

Ethical Statement: The authors are accountable for all aspects of the work in ensuring that questions related to the accuracy or integrity of any part of the work are appropriately investigated and resolved.

Open Access Statement: This is an Open Access article distributed in accordance with the Creative Commons Attribution-NonCommercial-NoDerivs 4.0 International License (CC BY-NC-ND 4.0), which permits the noncommercial replication and distribution of the article with the strict proviso that no changes or edits are made and the original work is properly cited (including links to both the formal publication through the relevant DOI and the license). See: https://creativecommons.org/licenses/by-nc-nd/4.0/.

\section{References}

1. Sihoe AD. The evolution of minimally invasive thoracic surgery: implications for the practice of uniportal thoracoscopic surgery. J Thorac Dis 2014;6:S604-17.

2. Ministry of Health. Health Annual Report, Palestine 2020. May 2021:48-9.

3. 2021 [cited 30 June 2021]. [Internet]. Available online: https://www.abms.org/board/american-board-of-thoracicsurgery/

4. Ministry of Health. Health Annual Report, Palestine 2020. May 2021:45-6.

5. Abu Akar F, Shaqqura B, Rumman N, et al. Subxiphoid uniportal video assisted thoracoscopic lobectomy in a pediatric patient. Mini-invasive Surg 2020;4:10.

6. Abu Akar F, Shaqqura B, Rumman N, et al. Uniportal video assisted thoracoscopic left upper bronchial sleeve lobectomy in a pediatric patient. Mini-invasive Surg 2020;4:25.

7. Nazzal K, Maree M, Ashhab H, et al. Total laparoscopic and uniportal thoracoscopic Ivor Lewis oesophagectomy with linear stapling anastomoses. Interact Cardiovasc Thorac Surg 2021;32:666.

8. Abu Akar F, Gonzalez-Rivas D. Training in an ultra-highvolume center. Video-assist Thorac Surg 2018;3:17.

9. Abu Akar F, Gonzalez-Rivas D, Shaqqura B, et al. Uniportal video assisted thoracoscopy versus open surgery for pulmonary hydatid disease—a single center experience. J Thorac Dis 2020;12:794-802.

10. Abd El-Hafez Fouly M, Zahra A, Ghalwash M. 
Thoracoscopy versus thoracotomy in hemodynamically stable patients with closed thoracic trauma. Journal of the Egyptian Society of Cardio-Thoracic Surgery. 2018;26:64-7.

11. 2021 [cited 30 June 2021]. [Internet]. Available online:

Cite this article as: Idkedek MI, Al-Qtishat BF, Shaqqura $\mathrm{BH}, \mathrm{Abu}$ Akar FE. Thoracic surgery in Palestine. J Thorac Dis 2022;14(5):1713-1718. doi: 10.21037/jtd-21-1139 https://www.ochaopt.org/

12. Shaqqura B, Rumman N, Gonzalez Rivas D, et al.

Uniportal video-assisted thoracoscopic lobectomy in a 9-week-old patient. Interact Cardiovasc Thorac Surg 2020;30:327. 